\title{
Research
}

\section{Patient centredness and the outcome of primary care consultations with patients with depression in areas of high and low socioeconomic deprivation}

\begin{abstract}
Background

Most patients with depression are managed in general practice. In deprived areas, depression is more common and poorer outcomes have been reported.
\end{abstract}

Aim

To compare general practice consultations and early outcomes for patients with depression living in areas of high or low socioeconomic deprivation

\section{Design and setting}

Secondary data analysis of a prospective observational study involving 25 GPs and 356 consultations in deprived areas, and 20 GPs and 303 consultations in more affluent areas, with follow-up at 1 month.

\section{Method}

Validated measures were used to (a) objectively

assess the patient centredness of

consultations, and (b) record patient perceptions of GP empathy.

\section{Results}

PHQ-9 scores $>10$ lsuggestive of caseness for moderate to severe depression) were

significantly more common in deprived than in affluent areas $(30.1 \%$ versus $18.5 \%, P<0.001)$. Patients with depression in deprived areas had more multimorbidity $165.4 \%$ versus $48.2 \%$ $P<0.05)$. Perceived GP empathy and observerrated patient-centred communication were significantly lower in consultations in deprived areas. Outcomes at 1 month were significantly worse (persistent caseness $71.4 \%$ deprived, $43.2 \%$ affluent, $P=0.011$. After multilevel multiregression modelling, observer-rated patient centredness in the consultation was predictive of improvement in PHQ-9 score in both affluent and deprived areas.

\section{Conclusion}

In deprived areas, patients with depression are more common and early outcomes are poorer compared with affluent areas. Patient-centred consulting appears to improve early outcome but may be difficult to achieve in deprived areas because of the inverse care law and the burden of multimorbidity.

\section{Keywords}

depression; multimorbidity; patientcentredness; primary care; socioeconomic status.
INTRODUCTION

Depression is the most common mental health disorder in community settings and a major cause of disability. ${ }^{1-3}$ It is projected to be the second leading cause of disease burden globally by $2030 .{ }^{4}$ Due to the high prevalence of depression, it is mostly managed in primary care. ${ }^{5}$

Socioeconomic deprivation is associated with an increased prevalence of depression, ${ }^{6-9}$ and with poorer outcomes. ${ }^{6,7}$ The inverse care law states that the availability of good medical care tends to vary inversely with the need for it in the population served. ${ }^{10}$ More recently, the inverse care law in the NHS of the UK has been described in terms of the mismatch of the steep social gradient of need against the flat distribution of the GP workforce. ${ }^{11-13} \mathrm{GP}$ encounters in deprived areas are characterised by greater complexity, less time, less patient enablement, and higher practitioner stress. ${ }^{14,15}$ GPs working in deprived areas can be reluctant to recognise and respond to depression. ${ }^{16}$

Patient centredness in GP consultations has been previously linked with improved patient trust, ${ }^{17}$ reduced diagnostic testing, ${ }^{18}$ and improved health outcomes. ${ }^{19}$ However, its influence and association with health outcomes for patients with depression in primary care has not been studied. It has been found that shared decision making in GP consultations with patients with depression improves participation and

B Jani, MRCS, MRCGP, SCREDS clinical lecture in general practice; AP Bikker; MSc, research assistant; M Higgins, BA, research assistant B Fitzpatrick, PhD, project manager; GCM Watt, MD, FRCP, FRCGP, FFPHM, FMedSci, professor of general practice; SW Mercer, PhD, FRCGP, chair of primary care research, General Practice and Primary Care, Institute of Health and Wellbeing. University of Glasgow, Glasgow. P Little, MD, MRCP, FRCGP. FMed Sci, professor of general practice, Primary Medical Care, University of Southampton, Aldermoor Health Centre, Southampton. patient satisfaction but has no effect on clinical outcomes. ${ }^{20}$

The objectives of the current study, which was a secondary data analysis, were to compare the prevalence of depression in patients consulting GPs in affluent and deprived areas, to describe consultations for depression in these areas, and to assess the impact of consultation characteristics on clinical outcomes after 1 month.

\section{METHOD}

Practices were recruited from the upper and lower quartile of deprivation (Scottish Index of Multiple Deprivation, SIMD 2006) in the Greater Glasgow and Clyde Area, Scotland, UK. ${ }^{21}$ The mean SIMD score for all practices in the upper quartile (68 practices) was 49 (range $=41-62$ ) and in the lower quartile 168 practices) was 14 (range $=5-22$ ).

Twenty practices, $47 \mathrm{GPs}$, and 659 patients participated (13 practices, $25 \mathrm{GPs}$, 356 patients in areas of high deprivation and seven practices, 22 GPs, 303 patients in areas of low deprivation). The mean practice size (number of registered patients) was 5108 and 7678 in the areas of high and low deprivation respectively $(P<0.01)$. The mean deprivation score (SIMD 2006) of all patients in participating practices was 46 (range $=$ $41-58$ ) and 13 (range $=5-22$ ) in the areas of high and low deprivation, respectively. The mean deprivation scores (SIMD 2006) of patients participating in this study were 49 (standard deviation $[\mathrm{SD}]=20$ ) and $14(\mathrm{SD}=$

\section{Address for correspondence}

Stewart W Mercer, General Practice and Primary Care, Institute of Health and Wellbeing, University of Glasgow, Glasgow, Scotland, G12 9LX

E-mail: Stewart.MercerAglasgow.ac.uk

Submitted: 23 December 2011; Editor's response: 19 January 2012; final acceptance: 8 March 2012. ()British Journal of General Practice

This is the full-length article (published online $30 \mathrm{Jul}$ 2012) of an abridged version published in print. Cite this article as: Br J Gen Pract 2012; DOI: 10.3399/bjgp12X653633. 


\section{How this fits in \\ The association between deprivation, consultation quality, and outcomes for patients with depression treated in primary care has not been previously studied. In a prospective study of 659 consultations in areas of high or low deprivation, 1-month outcomes las measured by the Patient Health Questionnaire [PHQ-9]) were markedly worse in patients living in deprived areas compared with those living in more affluent areas. In this secondary analysis, patient centredness in the consultation was an important predictor of early improvement in depressive symptoms and was lower in deprived areas compared with more affluent areas. Differences in GPs' approaches to patients with depression in deprived and more affluent areas may relate to the inverse care law and the burden of greater multimorbidity.}

15), in the areas of high and low deprivation, respectively. The age and sex of participating GPs did not differ significantly between the two areas. All practices operated on a 10 minute booking schedule for patient appointments, which is standard in the UK A total of $464(70 \%)$ of the 659 patients responded to the 1-month follow-up questionnaire $178 \%$ versus $63 \%$ for areas of low and high deprivation, respectively, $P<0.001)$

Ethical approval for the study was obtained from the local research ethics committee and informed consent was gained from all participating GPs and patients.

\section{Patient recruitment}

Reception staff gave consecutive patients laged $>17$ years) an information sheet when they checked in, and the research assistant gained signed informed consent. There were no exclusion criteria other than the need to be able to give signed informed consent in English. Fifty-three per cent of patients approached agreed to take part in the study $151 \%$ in high deprivation settings and $55 \%$ in low deprivation). GP consultations were video recorded. The aim of the study was to measure verbal and non-verbal communication in unselected consultations and to assess their impact on outcomes in affluent and deprived areas. This article presents the findings for patients with depression.

\section{Patient questionnaire at consultation and follow-up}

Patients completed a questionnaire at the time of first attendance, which included questions on demographic factors, the number of patient-reported chronic health conditions, the number and the nature of patient-reported presenting problems, and symptom severity and wellbeing assessed with the Measure Yourself Medical Outcome Profile (MYMOP) ${ }^{22}$ and the Patient Health Questionnaire (PHQ-9). ${ }^{23}$ It also included patient ratings of GP empathy as measured by the CARE (Consultation and Relational Empathyl measure, ${ }^{24}$ and patient-perceived enablement at the end of consultation as measured by the PEI (Patient Enablement Instrument). ${ }^{25}$

One-month follow-up on the MYMOP and PHQ-9 score was assessed by postal questionnaire (changes in MYMOP scores are being reported in a separate paper). A total of $464(70 \%)$ of the 659 patients responded to the 1-month follow-up questionnaire $178 \%$ versus $63 \%$ for areas of low and high deprivation, respectively); $61.3 \%$ of patients with depression caseness (100/163) responded to the follow-up questionnaire; 58.9\% (63/107) among depressed patients in deprived areas as compared to $66.1 \%(37 / 56)$ among those living in affluent areas. Table 1 compares the baseline characteristics of patients with depression between responders and nonresponders to the 1-month follow-up in affluent and deprived areas.

\section{Consultation video analysis}

Verbal communication was assessed by the Measure of Patient-Centred Communication (MPCC), which consists of three components lexploring disease and illness experience, understanding the whole person, and finding common groundl that are added to give a total score. ${ }^{26}$ This validated and widely used measure from the US has also been used in the UK. ${ }^{27}$ Three researchers coded the videos and regular inter-rater reliability checks were conducted. The average intraclass correlation (ICC) was 0.86 (compared with 0.73 as observed in previous studies using MPCC)..$^{19}$

Non-verbal communication was assessed with a modified version of Mehrabian's schemata. ${ }^{28,29}$ Categories included: number and duration of smiles, number of positive facial expressions, number of head nods, number of supportive gesticulations, gaze towards patient (duration measured in seconds), self/object manipulation (duration in seconds), and use of computer and notes (duration in seconds). The length of time it took to rate each consultation made it impractical to carry out this schedule on a large number of videos within the time 
Table 1. Baseline characteristics of responders and non-responders to follow-up at 1-month

\begin{tabular}{|c|c|c|c|c|c|c|}
\hline \multirow[b]{2}{*}{ Variable } & \multicolumn{3}{|c|}{ Affluent area } & \multicolumn{3}{|c|}{ Deprived area } \\
\hline & $\begin{array}{c}\text { Responders } \\
(n=37)\end{array}$ & $\begin{array}{c}\text { Non-responders } \\
(n=19)\end{array}$ & $P$-value & $\begin{array}{c}\text { Responders } \\
(n=3)\end{array}$ & $\begin{array}{c}\text { Non-responders } \\
(n=44)\end{array}$ & $P$-value \\
\hline Age, mean years (SD) & $50.2(17.9)$ & $46.37(14.7)$ & 0.14 & $46.6(15.3)$ & $41.1(16.5)$ & 0.20 \\
\hline Sex, \% female & 78.4 & 78.9 & 1.00 & 61.9 & 75 & 0.20 \\
\hline $\begin{array}{l}\text { Multimorbidity, } \% \text { with } \\
\geq 2 \text { chronic diseases }\end{array}$ & 45.9 & 52.6 & 0.77 & 68.3 & 61.4 & 0.53 \\
\hline $\begin{array}{l}\text { PHQ-9 at initial presentation, } \\
\text { mean (SD) }\end{array}$ & $14.2(4.9)$ & $15.2(4.9)$ & 0.99 & $15.3(4.3)$ & $15.6(4.7)$ & 0.39 \\
\hline CARE score, mean (SD) & 45.0 (7.3) & $45.6(5.9)$ & 0.35 & $42.5(6.9)$ & $43.8(6.7)$ & 0.20 \\
\hline MPCC, mean (SD) & $1.51(0.4)$ & $1.61(0.4)$ & 0.45 & $1.35(0.5)$ & $1.29(0.4)$ & 0.10 \\
\hline SIMD score, mean (SD) & 19.9 (19.0) & $24.0(17.7)$ & 0.95 & $52.6(16.9)$ & $51.9(16.0)$ & 0.37 \\
\hline
\end{tabular}

$C A R E=$ Consultation And Relational Empathy. MPCC $=$ Measure of Patient-Centred Communication. PHQ = Patient Health Questionnaire. SD = standard deviation.

$S I M D=$ Scottish Index of Multiple deprivation

constraints. A meta-analysis of studies using thin-slice judgements found that there was no significant difference in predictive accuracy between ratings based on 30seconds and 4-5-minute slices. ${ }^{30}$ For some variables, the first 30 -second slice was not significantly different from the average scores for the last 2 minutes (results not shown). Thus, a measurement schedule was chosen with a single 30-second slice 1 minute into the consultation and a 30second slice 1 minute from the end of the consultation. Two researchers coded the videos and two inter-rater reliability checks were conducted giving ICCs above 0.8.

The length of each consultation was recorded from the video recordings. All statistical analysis was carried out using the statistical software package SPSS (version 18).

\section{RESULTS}

Patient characteristics

The prevalence of depression was estimated using the PHQ-9 with a cut-off $\geq$ 10 to define caseness (moderate to severe depression). On this basis, 163 patients (24.6\%) were classified as having depression, which was higher in patients in

\section{Table 2. Patient characteristics}

\begin{tabular}{|c|c|c|c|}
\hline Variable & $\begin{array}{l}\text { Patients with depressive } \\
\text { symptoms in deprived areas } \\
\text { (n=107), number }(\%)\end{array}$ & $\begin{array}{l}\text { Patients with depressive } \\
\text { symptoms in affluent areas } \\
\text { (n=56), number }(\%)\end{array}$ & $P$-value \\
\hline \multicolumn{4}{|l|}{ Age, years } \\
\hline$<40$ & 33 (30.8) & 23 (41.1) & 0.104 \\
\hline $40-64$ & $54(50.5$ & 27 (48.2) & \\
\hline$>65$ & 20 (18.7) & $6(10.7)$ & \\
\hline \multicolumn{4}{|l|}{ Sex } \\
\hline Male & 35 (32.7) & $12(21.4)$ & 0.114 \\
\hline Female & 72 (67.3) & $44(78.6)$ & \\
\hline $\begin{array}{l}\text { Multimorbidity, } \\
\geq 2 \text { long-term conditions }\end{array}$ & 70 (65.4) & 27 (48.2) & 0.040 \\
\hline
\end{tabular}

deprived areas compared with affluent areas; $30.1 \%(107 / 356)$ versus $18.5 \%$ (56/303) respectively $(P<0.001)$.

The characteristics of the 163 patients with depression in the deprived and affluent areas are shown in Table 2. Multimorbidity (the coexistence of two or more chronic health conditions) was significantly more common in patients with depression living in deprived areas compared with the affluent areas; $65.4 \%$ (70/107) versus $48.2 \%$ (27/56) respectively $(P=0.04)$.

Of the depressed patients, $60.7 \%$ (65/107) living in deprived areas wished to discuss two or more problems with their GPs, compared to $52.7 \%$ of patients (29/55) living in affluent areas ( $P=0.10)$.

Of the patients with depression living in deprived areas, 42.1\% (45/107) reported that they had an 'emotional problem' to discuss with their GPs, compared with 47.3\% (26/55) of patients living in affluent areas $(P=$ 0.528).

Persistence of depression caseness at 1 month follow-up was $71.4 \%$ (45/63) in deprived areas, compared with $43.2 \%$ (16/37) in affluent areas $(P=0.005)$. The mean improvement in $\mathrm{PHQ}-9$ in individuals with depression was 4.87 (14.55 to 9.68) in affluent areas, compared with 0.9 (15.4 to $14.5)$ in deprived areas ( $P=0.018)$.

\section{Consultation characteristics}

Five different measures of the consultation were employed to compare patients with PHQ-9 caseness in affluent and deprived areas (Table 3)

The patients' perception of the GP's empathy was assessed by the CARE measure. Mean CARE measure scores were significantly lower in patients with caseness living in deprived areas compared with those in affluent areas $(P=0.003)$.

Objective measurement of the verbal 
Table 3. Consultation characteristics of patients with depressive symptoms

\begin{tabular}{|c|c|c|c|}
\hline Variable & $\begin{array}{c}\text { Deprived areas, } \\
\text { mean (SD) }\end{array}$ & $\begin{array}{c}\text { Affluent areas, } \\
\text { mean (SD) }\end{array}$ & $P$-value \\
\hline CARE & $43.0(6.80)$ & $45.2(6.80)$ & 0.003 \\
\hline$\overline{\mathrm{PEI}}$ & $3.57(0.32)$ & $4.19(0.42)$ & 0.254 \\
\hline Consultation length, minutes & $9.16(4.24)$ & $10.25(4.90)$ & 0.151 \\
\hline How well the patient knows the GP, score & $4.03(1.02)$ & $3.65(1.21)$ & 0.081 \\
\hline \multicolumn{4}{|l|}{ Verbal skills } \\
\hline MPCC, global score & $1.32(0.45)$ & $1.54(0.43)$ & 0.004 \\
\hline Component 1 , score & $0.258(0.13)$ & $0.321(0.14)$ & 0.005 \\
\hline Component 2, score & $0.327(0.37)$ & $0.426(0.35)$ & 0.101 \\
\hline Component 3 , score & $0.74(0.17)$ & $0.81(0.13)$ & 0.009 \\
\hline \multicolumn{4}{|l|}{ Non-verbal skills } \\
\hline Number of seconds looking at the patient & $18.22(10.02)$ & $24.73(7.35)$ & 0.002 \\
\hline Number of head nods & $4.03((5.66)$ & $6.71(5.55)$ & 0.001 \\
\hline Number of positive facial expressions & $1.15(1.39)$ & $1.82(1.67)$ & 0.013 \\
\hline
\end{tabular}

patient centredness of the GPs using the MPCC showed a significantly lower mean global score in patients with caseness in deprived areas compared with affluent areas $(P=0.004)$. Mean scores for components one lexploring disease and illness experience) and three (finding common ground) were significantly lower in deprived areas as compared to those in affluent areas (Table 3).

Statistically significant differences between patients with caseness in deprived areas compared with affluent areas were found for three parameters of the GP's nonverbal behaviour; GPs in deprived areas looked at the patients less, had fewer head nods, and had fewer positive facial expressions (Table 3).

Patient enablement (mean PEI score) and mean consultation length for patients with caseness living in deprived areas were not significantly different from those of patients living in affluent areas (Table 3).

\section{Factors predictive of follow-up PHQ-9} score

Considering the hierarchical nature of data, linear mixed-model or multilevel modelling

\begin{tabular}{|c|c|c|c|}
\hline Independent variable & Effect estimate & $95 \% \mathrm{Cl}$ & $P$-value \\
\hline Deprivation & 4.36 & 1.21 to 7.52 & 0.004 \\
\hline Age & -0.11 & -0.20 to -0.10 & 0.025 \\
\hline Initial PHQ-9 & 0.65 & 0.32 to 0.96 & 0.001 \\
\hline MPCC score & -3.10 & -6.1 to -0.7 & 0.037 \\
\hline Sex & -2.32 & -5.35 to 0.71 & 0.116 \\
\hline CARE score & 0.58 & -1.42 to 2.58 & 0.824 \\
\hline
\end{tabular}

was used for regression analysis. The follow-up PHQ-9 score was used as the target predictor variable and the individual GP was used as a grouping variable to control clustering effects of patients around individual GPs.

The following variables were entered in the analysis: age of the patient, sex of the patient, deprivation score, and index $\mathrm{PHQ}-9$ score. The effect of adding the individual measures of the consultation (CARE score, PEI, MPCC score, and the non-verbal variables) was then tested in a series of models. As shown in Table 4, the patient's age, deprivation status, and initial $\mathrm{PHQ}-9$ score were significantly associated with the follow-up PHQ-9 score. Overall MPCC score (overall verbal patient centredness) also had a significant effect on follow-up PHQ-9 score, whereas the CARE measure did not. Replacing the overall MPCC score by each of the individual three components did not show any significant effects in predicting follow-up PHQ-9 (results not shown).

To explore whether the predictive effect of observer-rated verbal patient centredness on follow-up PHQ-9 score was similar in deprived and affluent areas, an interaction effect between deprivation score and MPCC was added to the regression analysis. This showed an insignificant influence $(P=$ 0.438), implying that the effect of overall MPCC score in predicting follow-up PHQ-9 was not influenced by the deprivation status of the patient.

\section{DISCUSSION}

\section{Summary}

This study compared GP consultations involving patients with depression living in affluent and deprived areas, and the early outcomes of these encounters. Depressive symptoms were significantly more common in patients from deprived areas, and outcomes at 1 month were significantly worse. Several aspects of observer-rated verbal and non-verbal patient-centred communication by the GPs, and patientperceived empathy, were significantly lower in consultations in deprived areas. In multilevel multiregression modelling, the overall verbal patient centredness of the consultation was predictive of improvement in $\mathrm{PHQ}-9$ score.

\section{Strengths and limitations}

The present study was large and applied a battery of validated observer-rated and patient-rated measures of the consultation. By comparing deprivation scores (SIMD) of practice populations and patients, it was possible to demonstrate that the patients 
who participated were representative of the registered patients in the participating practices, and that the participating practices were representative of the eligible practices in the sampling frame.

All of the practices in the study serving deprived areas are part of the Deep End Project, based on the 100 most deprived general practices in Scotland. ${ }^{31}$ The research findings support the views and experience of 'Deep End' GPs, in terms of both the high prevalence of psychological comorbidity within routine consultations, 32 and the lack of time to address adequately the multimorbidity that many patients present. ${ }^{33}$

The study was a secondary data analysis and hence study design and size were not conceived for depression alone. The followup duration was relatively short at 1 month; however, early patterns of treatment response in depression are known to be predictive of longer-term outcomes. ${ }^{34}$

Although one-third of patients were lost to follow-up in both affluent and deprived areas, there was no significant different between responders and non-responders in the patient and consultation characteristics included in the regression analysis (Table 1). The study is also limited by the sensitivity and specificity of $\mathrm{PHQ}-9$ as a measure of depressive symptoms. However, it remains a widely used scale in general practice research.

\section{Comparison with existing literature}

The management of patients with depression in primary care is an area of ongoing international research. ${ }^{35}$ In previous studies, the measure of observed patient centredness used in the present study (the MPCCl has been linked to patient satisfaction, ${ }^{27}$ reduced diagnostic testing, ${ }^{18}$ and improved patient health status. ${ }^{19}$

There is substantial evidence of the beneficial effects of practitioner empathy on the outcomes of consultations with patients with mental health problems. ${ }^{36-39}$ Patientperceived empathy as measured by the CARE measure has been linked to patient enablement and health outcomes. ${ }^{40,41}$ In the present study, although there was a significant difference between CARE scores in patients with depression living in affluent and deprived areas, these scores were not related to follow-up PHQ-9 score. This may be an issue related to sample size, as the original study was not powered to detect the effect of empathy on outcomes in patients with depression.

Longer consultations in primary care are associated with higher accuracy of diagnosis of psychological problems. ${ }^{42}$ Increased consultation time for patients with complex problems in deprived areas has been associated with increased patient enablement and lower GP stress. ${ }^{43}$ Consultation length in the present study did not differ significantly between deprivation groups. However, in the authors' previous work with a larger sample of over 3000 patients in the same setting, ${ }^{14}$ shorter consultation lengths were found in deprived areas.

\section{Implications for practice and research}

The importance of patient centredness to outcomes has important implications, as do the factors that limit this in areas of high deprivation, as described in recent reports on the challenges facing GPs working in the most deprived areas of Scotland (the 'Deep End').31-33,44 Reducing the inverse care law, by the provision of substantially larger numbers of GPs in deprived areas, may be challenging at this time of tight financial restraint in the NHS, yet ways of providing more time and support for practitioners in deprived areas are urgently needed, to stem the unmet needs of patients with depressive symptoms and other problems relating to multimorbidity.

For patients living in deprived areas, depressive symptoms are more common and early outcomes are poorer compared with patients consulting GPs in more affluent areas. Patient-centred consulting appears to improve early outcome but may be difficult to achieve in deprived areas because of the inverse care law, and higher need due to multimorbidity and the resultant time pressures on GPs. Reversing the inverse care law remains a key policy imperative.

\section{Acknowledgments}

We are grateful to all the GPs and patients who participated in this study.

\section{Discuss this article}

Contribute and read comments about this article on the Discussion Forum: http://www.rcgp.org.uk/bjgp-discuss 


\section{REFERENCES}

1. Andrade L, Caraveo-Anduaga JJ, Berglund P, et al. Epidemiology of major depressive episodes. Results from the International Consortium of Psychiatric Epidemiology (ICPE) Surveys. Int J Methods Psychiatr Res 2003; 12(1): 3-21.

2. Kessler RC, Berglund P, Demler O, et al. Lifetime prevalence and age-ofonset distributions of DSM-IV disorders in the National Co-morbidity Survey Replication. Arch Gen Psychiatry 2005; 62(6): 593-602.

3. Kessler RC, Chiu WT, Demler O, et al. Prevalence, severity, and comorbidity of 12-month DSM-IV disorders in the National Comorbidity Survey Replication. Arch Gen Psychiatry 2005; 62(6): 617-627.

4. Mathers CD, Loncar D. Projections of global mortality and burden of disease from 2002 to 2030. PLoS Med 2006; 3(11): e442.

5. Goldberg DP, Huxley P. Mental illness in the community. The pathway to psychiatric care. London: Tavistock, 1980.

6. Ostler K, Thompson C, Kinmonth AL, et al. Influence of socio-economic deprivation on the prevalence and outcome of depression in primary care: The Hampshire Depression Project. Br J Psychiatry 2001; 178(1): 12-17.

7. Lorant V, Croux C, Weich S, et al. Depression and socio-economic risk factors: 7-year longitudinal population study. Br J Psychiatry 2007; 190: 293-298.

8. Gunn JM, Gilchrist GP, Chondros $P$, et al. Who is identified when screening for depression is undertaken in general practice? Baseline findings from the Diagnosis, Management and Outcomes of Depression in Primary care (Diamond) longitudinal study. Med J Aust 2008; 188(12 suppl): S119-S125.

9. Paczkowski M, Galea S. Sociodemographic characteristics of the neighbourhood and depressive symptoms. Curr Opin Psychiatry 2010; 23(4): 337-341.

10. Hart JT. The inverse care law. Lancet 1971; 1(7696): 405-412.

11. Watt G. The inverse care law today. Lancet 2002; 360(9328): 252-253,

12. Carlisle R, Avery AJ Marsh P. Primary care teams work harder in deprived areas. J Public Health 2002; 24(1): 43-48.

13. Campbell SM, Hann M, Hacker J, et al. Identifying predictors of high quality care in English general practice: observational study. BMJ 2001; 323(7316): 784-789.

14. Mercer SW, Watt GC. The inverse care law: clinical primary care encounters in deprived and affluent areas of Scotland. Ann Fam Med 2007; 5(6): 503-510.

15. Stirling AM, Wilson P, McConnachie A. Deprivation, psychological distress, and consultation length in general practice. Br J Gen Pract 2001: 51(467): 456-460.

16. Chew-Graham CA, Mullin S, May CR, et al. Managing depression in primary care: another example of the inverse care law? Fam Pract 2002; 19(6): 632-637.

17. Fiscella K, Meldrum S, Franks $P$, et al. Patient trust: is it related to patientcentered behaviour of primary care physician? Med Care 2004; 42(11): 1049-1055.

18. Epstein RM, Franks $P$, Shields CG, et al. Patient-centered communication and diagnostic testing. Ann Fam Med 2005; 3(5): 415-421.

19. Stewart M, Brown JB, Donner A, et al. The impact of patient-centered care on outcomes. J Fam Pract 2000; 49(9): 796-804.

20. Loh A, Simon D, Wills CE, et al. The effects of shared decision-making intervention in primary care of depression: a cluster-randomized controlled trial. Patient Educ Couns 2007; 67(3): 324-332.

21. The Scottish Government. Scottish Index of Multiple Deprivation 2006: technical report. Edinburgh: Office of the Chief Statistician, Scottish Executive, 2006.

22. Paterson C. Measuring outcomes in primary care: a patient generated measure (MYMOP) compared with the SF-36 health survey. BMJ 1996 312(7037): 1016-1020.

23. Spitzer R, Kroenke K, Williams J. Validation and utility of a self-report version of PRIME-MD: the PHQ Primary Care Study. JAMA 1999; 282(18): 1737-1744

24. Mercer SW, Maxwell M, Heaney D, Watt GC. The development and preliminary validation of the Consultation and Relational Empathy (CARE) Measure: an empathy-based consultation process measure. Fam Pract 2004: 21(6): 699-705.

25. Howie JG, Heaney DJ, Maxwell M, Walker JJ. A Comparison of a Patient Enablement Instrument (PEI) against two established satisfaction scales as an outcome measure of primary care consultations. Fam Pract 1997: 15(2): 165-171.

26. Brown J, Stewart M, Ryan BL. Assessing communication between patients and physicians: the Measure of Patient-Centered Communication (MPCC) (2nd edn). Working Paper Series, Paper 95-2. 2nd edn. Ontario: Centre for Studies in Family Medicine, 2001.

27. Kinnersley P, Stott N, Peters T, Harvey I. The patient-centredness of consultations and outcome in primary care. Br J Gen Pract 2000; 49(446) $11-16$.

28. Mehrabian A, Epstein N. A measure of emotional empathy. J Pers 1972; 40(4) 525-543.

29. DiMatteo MR, Hays RD, Prince LM. Relationship of physicians' nonverbal communication skill to patient satisfaction, appointment noncompliance, and physician workload. Health Psychol 1986; 5(6): 581-594

30. Ambady N, Rosenthal R. Thin slices of expressive behaviour as predictors of interpersonal consequences: a met-analysis. Psychol Bull 1992; 111(2): 256-274.

31. Watt G. A social institution based on mutuality and trust. Br J Gen Pract 2011; 61(593): 741 .

32. Watt G. Patient encounters in very deprived areas. Br J Gen Pract 2011; 61(583): 146 .

33. Watt G. Time to make a difference. Br J Gen Pract 2011; 61(590): 569

34. Lutz W, Stulz N, Köck K. Patterns of early change and their relationship to outcome and follow-up among patients with major depressive disorders. $J$ Affect Disord 2009; 118(1-3): 60-68.

35. Gunn J, Palmer V, Dowrick C, et al. Embedding effective depression care: using theory for primary care organisational and system change. Implement Sci 2010; 5: 62.

36. Hartley D, Strupp H. The therapeutic alliance: its relationship to outcome in brief psychotherapy. In: Masling J (ed.). Empirical studies of psychoanalytic theories. Hillside, NJ: Erlbaum, 1986: 1-27.

37. Orlinsky DE, Grawe K, Parks BK. Process and outcome in psychotherapy noch einmal. In: Bergin AE, Garfield SL (eds.). Handbook of psychotherapy and behaviour change (4th edn). New York: Wiley, 1994: 270-376.

38. Burns DD, Nolen-Hoeksema S. Therapeutic empathy and recovery from depression in cognitive behavioural therapy: a structural equation model. $J$ Consult Clin Psychol 1992; 60(3): 441-449

39. Bohart AC, Elliot R, Greenberg LS, Watson JC. Empathy. In: Norcross JC (ed.). Psychotherapy relationships that work: therapist contributions and responsiveness to patients. New York: Oxford University Press, 2002: 89-108.

40. Neumann M, Wirtz M, Bollschweiler E, et al. Determinants and patientreported long-term outcomes of physician empathy in oncology: a structural equation modelling approach. Patient Educ Couns 2007; 69(1-3): 63-75.

41. Mercer SW, McConnachie A, Maxwell M, et al. Relevance and performance of the Consultation and Relational Empathy (CARE) Measure in general practice. Fam Pract 2005; 22(3): 328-334

42. Hutton C, Gunn J. Do longer consultations improve the management of psychological problems in general practice? A systematic literature review. BMC Health Serv Res 2007; 7: 71

43. Mercer SW, Fitzpatrick B, Gourlay G, et al. More time for complex consultations in a high deprivation practice is associated with increased patient enablement. Br J Gen Pract 2007; 57(545): 960-966.

44. Norbury M, Mercer SW, Gillies J, et al. Time to care: tackling health inequalities through primary care [Editorial]. Fam Pract 2011; 28(1): 1-3. 